\title{
Modelo Empírico de Predição de Perdas em Ambientes Fechados
}

\author{
Cláudio Garrido Muzis Sobrinho, Francisco Madeiro, Marcelo S. Alencar e Waslon Terllizzie A. Lopes
}

\begin{abstract}
Resumo-Este artigo apresenta um estudo de caso de medição de sinais de radio frequência realizado em um ambiente fechado. Como resultado, são propostos dois modelos de predição de perda de propagação de ondas baseados na recepção de sinais WiFi, que podem ser usados para a construção de um sistema de localização em ambientes fechados.
\end{abstract}

Palavras-Chave-Modelo de Propagação; Ambientes Fechados; Rede Local Sem Fio (WLAN); WiFi.

Abstract-This paper presents a case study featuring radiofrequency signal measurement in an indoor environment. As a result, two loss predicion models are proposed based on the reception of WiFi signals, which can be used to construct an indoor location system.

Keywords-Propagation Model; Indoor Enviromments; Wireless Local Area Network (WLAN); WiFi.

\section{INTRODUÇÃO}

A disseminação de dispositivos móveis de comunicações portáteis tem causado grande desenvolvimento de sistemas e serviços de localização considerando ambientes fechados. Com seus recursos de conectividade, praticidade e comunicação, esses dispositivos como: assistente pessoal digital (PDA - Personal Digital Assistant), notebooks, aparelhos celulares e pen drives, passaram a ser imprescindíveis na vida das pessoas.

Logo, essa nova realidade propicia inúmeras alternativas a serem exploradas e tem influência em diversas áreas de pesquisas. Um dos setores que tem bastante interesse nesses últimos tempos, devido o aumento da capacidade dos processadores, é a de aplicativos que tem em consideração o contexto em que estão inseridos. Decerto esses aplicativos orientados a contexto têm autonomia de escolher como e quando quer se comunicar com o usuário, pois possuem informações importantes sobre a circunstância em que o dispositivo e o usuário se deparam. Esses dispositivos, na maioria das vezes, possuem sistemas de localização em relação à atividade e as metas que o usuário anseia. Com isso, toda vez que um aplicativo orientado é usado em um dispositivo móvel, um dado que pode ser útil para esse processo é a informação do posicionamento desse dispositivo no ambiente em que ele se encontra [9].

Cláudio Garrido Muzis Sobrinho e Waslon Terllizzie A. Lopes, Curso de Engenharia Elétrica, ÁREA1 - Faculdade de Ciência e Tecnologia, Salvador, BA, Brasil, E-mails: cau.garrido@gmail.com e waslon@ieee.org.

Francisco Madeiro, Núcleo de Pesquisa em Telecomunicações (NPT), Escola Politécnica de Pernambuco (POLI), Universidade de Pernambuco (UPE), Recife, PE, Brasil, E-mail: franciscomadeiro@yahoo.com.br.

Marcelo S. Alencar, Departamento de Engenharia Elétrica, Universidade Federal de Campina Grande, Instituto de Estudos Avançados em Comunicações (Iecom), Campina Grande, PB, Brasil, E-mails: malencar@iecom.org.br e malencar@dee.ufcg.edu.br.
Atualmente, diversos aplicativos demandam serviços baseados em localização (SBLs) em ambientes fechados (indoor) e estão prontamente sendo utilizados, como: a monitorização de funcionários, guias turísticos "virtuais" para museu, auxílio a deficientes físicos, aplicativos de roteamentos, dentre outros [4] [12].

Existem diversas técnicas de localização para dispositivos móveis, entre as quais tecnologias podem citar o Sistema de Posicionamento Global (GPS Global Positioning System), algumas tecnologias usadas pelas companhias de celulares, redes de sensores de infravermelho, ultra-som e muitas outras [10]. O maior problema relacionado a esses sistemas é a questão da sua viabilidade, relacionada às limitações técnica e o alto custo de implantação, para inferência da localização de dispositivo móvel em ambiente indoor.

O sistema de localização mais difundido e conhecido é o GPS, é um dos mais precisos métodos para determinar o posicionamento do dispositivo. O problema do GPS é a dificuldade nas aplicações em ambientes indoor, pois os sinais dos satélites não atravessam barreiras sólidas, assim eles não podem ser utilizados em determinadas aplicações. Uma possível alternativa para o GPS é a utilização de um sistema que aplica a infra-estrutura pré-estabelecida baseado na intensidade dos sinais de rádio freqüência $(\mathrm{RF})$ de uma rede local sem fio (WLAN) que atualmente está bem difundida e cujos custos estão sempre diminuindo.

O propósito deste artigo é o desenvolvimento de um modelo de predição das perdas de propagação em ambientes fechados para ser utilizado como entrada nos sistema de localização. $O$ restante deste artigo encontra-se organizado da seguinte forma: A Seção II apresenta o conceito de localização baseado em sinais WiFi. Os modelos de propagação são discutidos na Seção III enquanto a Seção IV apresenta o ambiente de teste utilizado neste trabalho. Por fim, resultados e conclusões são apresentados nas Seções V e VI, respectivamente.

\section{LOCALIZAÇÃO COM WIFI}

$\mathrm{O}$ termo WiFi (Wireless Fidelity) refere-se às redes e dispositivos móveis que obedecem as especificações do padrão IEEE 802.11 para redes locais sem fio (WLAN - Wireless Local Area Networks). O padrão opera nas faixas de frequência de 2,4 ou 5,0 GHz, conhecidas respectivamente como banda ISM (Industrial, Scientific and Medical) e U-NII (Unlicensed National Information Infrastructure), cuja utilização não exige licença da ANATEL [1].

O conjunto de técnicas de localização de dispositivos móveis baseados na exploração dos sinais WiFi, denominado 
de localização WiFi, apresenta-se como uma boa alternativa para aplicações em ambientes indoor. Uma de suas principais características é o baixo custo, pois não requer a instalação de dispositivos dedicados à tarefa de localização, usados em tecnologias como redes de sensores de infravermelho e ultrasom (radar) [10]. O Sistema de Posicionamento Global (GPS) não apresenta bom desempenho em aplicações indoor, pois os sinais dos satélites são fortemente atenuados ao atravessar construções.

Neste contexto, os sinais de radiofrequência (RF) de uma rede WiFi são mais adequados ao propósito de localização em interiores. Três atributos dos sinais de RF que são transmitidos pelos pontos de acesso (AP - Access Point) e captados pelos dispositivos móveis podem ser utilizados em um sistema de posicionamento: o tempo que o sinal leva para chegar ao receptor, o ângulo de incidência e a potência com que esse sinal é recebido (RSSI - Received Signal Strength Indication).

Neste trabalho, para inferir a posição do dispositivo móvel no ambiente indoor, é utilizada a informação da potência do sinal (RSSI), pois os sinais nesses ambientes têm a característica de propagação por múltiplos percursos e seguem um modelo de propagação NLOS (Non-Line of Sight), que não inclui o caminho em linha reta [9]. Com isso é difícil utilizar os outros dois atributos (tempo e ângulo de incidência do sinal transmitido), para um ambiente com uma alta complexidade estrutural.

Com a informação RSSI e um modelo de predição das perdas de propagação de ondas é possível estimar a distância entre o dispositivo e os APs, que constituem os pontos de referências do sistema. Logo, o principio básico do sistema de Localização WiFi funciona baseado nos sinais de diversos APs. O dispositivo móvel recebe o sinal de pelo menos três APs e triangula a posição requerida [14].

\section{Modelos de PropagaçÃo}

A comunicação em uma WLAN entre um AP e o dispositivo móvel é baseada em sinais de RF que são atenuados em seu caminho (path losses) de propagação em função das características de cada ambiente [13]. A relação entre as perdas de propagação e a distância entre o transmissor e o receptor é fundamental no desenvolvimento de um sistema de localização que usa WLAN [11].

Esta seção apresenta os modelos de propagação que caracterizam as perdas ocasionadas pelos fenômenos de propagação [7]. Além de modelos encontrados na literatura, também são propostos dois modelos baseados em técnicas de regressão.

\section{A. Modelos da literatura}

1) Perda de propagação em espaço livre: A Equação de Friis serve de base para a maioria dos modelos pois provê uma estimativa inicial das perdas de propagação das ondas eletromagnéticas [15].

Denomina-se propagação em espaço-livre quando não existem obstáculos entre a antena transmissora e a antena receptora. Deste modo, a única atenuação prevista é o espalhamento da energia que é radiada pela antena em uma superfície esférica de raio $d$ cuja área lateral é igual $4 \pi d^{2}$ [7].
A Equação de Friis para a perda de propagação em espaçolivre é dada por

$$
L=-10 \log \frac{W_{R}}{W_{T}}=-10 \log \left[G_{R} G_{T}\left(\frac{\lambda}{4 \pi d^{2}}\right)^{2}\right],
$$

em que

- $G_{T}=G_{R}=1$ : ganho unitário para uma antena isotrópica;

- $S=10 \log \frac{W_{R}}{0,001}$ : potência recebida em dBm;

- $10 \log \frac{W_{T}}{0,001}=18 \mathrm{dBm}$ : potência transmitida pelo AP.

A Equação de Friis pode ser re-escrita como

$S=18+20 \log \left(\frac{c}{4 \pi f d}\right)=18+20 \log \left(\frac{c}{4 \pi f}\right)-20 \log d$,

em que $c$ é a velocidade na luz no vácuo $(300.000 .000 \mathrm{~m} / \mathrm{s})$ e $f$ é a freqüência do sinal, igual a $2,4 \mathrm{GHz}$ (em virtude do Padrão 802.11 b, adotado neste trabalho para realização do experimento).

Sendo assim, a distância em função da potência recebida é

$$
d_{\text {Friis }}=10^{\frac{-22,05-S}{20}} \text {. }
$$

Como o sinal recebido em $\mathrm{dBm}$ tem o valor negativo, foi utilizado o módulo do valor de potência do sinal. Desta forma, faz-se uma pequena modificação na Equação 4

$$
d_{\text {Friis }}=10^{\frac{-22,05+S}{20}} \text {. }
$$

O modelo de Friis apresenta pouca aplicabilidade em ambientes indoor em virtude dos possíveis obstáculos que geram a propagação em múltiplos percursos [3]. Contudo, é possível editar variações no modelos de Fris, para locais com propagações não ideais, sendo estas variações adequadas para lugares amplos, como ruas e avenidas [5].

A equação genérica de Friis, tendo como base o resultado de Motley [8], é usada para comparação com os resultados experimentais, em que se varia $n$.

$$
L=-10 \log \frac{W_{R}}{W_{T}}=-10 \log \left[G_{R} G_{T}\left(\frac{\lambda}{4 \pi d^{2}}\right)^{n}\right] .
$$

Pode-se obter a equação da distância em função da potência recebida,

$$
d_{\text {Friis }(n)}=10^{\frac{K_{\text {Friis }}+S}{10 n}},
$$

em que $K_{\text {Friis }}$ é dado por

$$
K_{\text {Friis }}=S_{T}+10 n \log \left(\frac{c}{4 \pi f}\right)
$$

De acordo com os dados do fabricante do AP, a potência transmitida é igual a $S_{T}=18 \mathrm{dBm}$.

2) Modelo da Recomendação ITU-R P.1238-1: O modelo descrito pela União Internacional de Telecomunicações, ITU (International Telecommunication Union) é considerado site-general, (ITU-R P.1238-1), pois necessita de poucas informações sobre o ambiente de teste, como a identificação do tipo do local a ser explorado [11].

Esse modelo foi projetado para predições de perda da propagação de ondas em ambientes indoor que utilizam as faixas de frequências entre $900 \mathrm{MHz}$ e $100 \mathrm{GHz}$. 
Os efeitos de propagação estão previstos no modelo e consideram os mecanismos de reflexão e difração nos obstáculos, a propagação por múltiplos percursos, a energia confinada nos corredores, além dos fenômenos aleatórios que são proporcionados pelos movimentos das pessoas e dos objetos [2].

Neste modelo, a perda por propagação é dada por

$$
L_{I T U}=20 \log f_{\mathrm{MHz}}+N \log d_{\mathrm{m}}+L_{f}(n)-28,
$$

em que $f_{\mathrm{MHz}}$ é a frequiência do sinal transmitido (em $\mathrm{MHz}$ ), $d_{\mathrm{m}}$ representa a distância entre o receptor e o transmissor (em metros), $N$ é o coeficiente de atenuação da potência em relação à distância e $L_{f}$ é o fator que determina a atenuação por penetração das ondas eletromagnéticas entre andares.

A perda devido à propagação entre andares foi considerada nula, $L_{f}(n)=0$, pois as medições realizadas foram feitas em um único piso, i.e., no mesmo pavimento em que encontravam os APs.

O coeficiente de atenuação $N$ depende da frequência de operação bem como do tipo de estabelecimento em que a rede WiFi encontra-se instalada, de acordo com a Tabela I.

TABELA I

Coeficiente de atenuAÇão $N$ RECOMENDAdo PELA ITU [6].

\begin{tabular}{c|c|c|c}
\hline Frequência & Residencial & Escritório & Comercial \\
\hline $900 \mathrm{MHz}$ & - & 33 & 20 \\
\hline $1,2-1,3 \mathrm{GHz}$ & - & 32 & 22 \\
\hline $1,8-2,0 \mathrm{GHz}$ & 28 & 30 & 22 \\
\hline $4,0 \mathrm{GHz}$ & - & 28 & 22 \\
\hline $5,2 \mathrm{GHz}$ & - & 31 & - \\
\hline $60 \mathrm{GHz}$ & - & 22 & 17 \\
\hline
\end{tabular}

As medições foram feitas em um imóvel comercial. Sendo assim, com base na Tabela I, o parâmetro $N$ escolhido foi 22 $\mathrm{dBm}$, pois a portadora $\mathrm{RF}$ utiliza a faixa de frequência de 2,4 $\mathrm{GHz}$, que se aproxima da faixa de $2 \mathrm{GHz}$.

A distância em relação ao módulo da potência do sinal recebido é

$$
d_{\mathrm{ITU}}=10^{\frac{S+K_{\mathrm{ITU}}}{N}}
$$

em que $K_{\mathrm{ITU}}$ é dado por

$$
K_{\mathrm{ITU}}=-S_{T}-20 \log \left(f_{\mathrm{MHz}}\right)+28
$$

em que $S_{T}=18 \mathrm{dBm}$ é potência transmitida pelo AP. Finalmente, a equação que aplica a esse ambiente é

$$
d_{\mathrm{ITU}}=10^{\frac{S-57,6}{22}} \quad(\mathrm{~dB}) .
$$

3) Modelo WPS: O modelo WPS (Wireless Positioning Systems) [14] utiliza uma técnica de regressão polinomial de grau cúbica, cuja distância é dada por

$$
d_{\mathrm{WPS}}=0,000198 S^{3}-0,025 S^{2}+1,14 S-14,8,
$$

em que $d_{\text {WPS }}$ é a distância em metros e $S$ é o módulo da potência do sinal recebido em $\mathrm{dBm}$.

\section{B. Modelos Propostos}

Neste trabalho são propostos dois modelos de regressão para estimar as perdas de propagação em redes WiFi: regressão exponencial e regressão geométrica. Os parâmetros dos modelos são determinados a partir de técnicas de linearização, em que um conjunto de dados experimentais é usado para obter curvas que minimizam o erro entre os valores calculados e os valores medidos. Com a representação dos pontos pode-se identificar qual o tipo de curva ou tendência acompanha os dados empíricos. Os modelos são apresentados a seguir.

1) Regressão Exponencial: A equação que representa a regressão exponencial é

$$
d_{\mathrm{REX}}=a e^{b S},
$$

em que $d_{\text {REX }}$ é a distância em metros (m) e $S$ é o módulo da potência recebida em $\mathrm{dBm}$. Aplicando o logaritmo neperiano na Equação 13 obtém-se

$$
\ln d_{\mathrm{REX}}=\ln a+b S,
$$

que representa uma equação afim e descreve uma reta.

Com base no conjunto de dados experimentais, foram encontrados os parâmetros de interceptação $(\ln a)$ e inclinação (b) desta reta e os seus valores foram: $\ln a=-0,420049 \mathrm{e}$ $b=0,045195$. Desta forma, tem-se $a=e^{-0,420049}$.

Substituindo na Equação 13, chega-se a

$$
d_{\mathrm{REX}}=a e^{b S}=0,657014625 e^{0,045195 S} .
$$

2) Regressão Geométrica: A equação matemática que representa esta regressão geométrica é

$$
d_{\mathrm{RPO}}=a S^{b}
$$

em que $d_{\mathrm{RPO}}$ é a distância em metros (m) e $S$ é o módulo da potência recebida em $\mathrm{dBm}$. Aplicando o logaritmo na base 10 na Equação 16, obtém-se

$$
\log d_{\mathrm{RPO}}=\log a+b \log S .
$$

Com base no conjunto de dados obtido no experimento, foram encontrados os parâmetros de interceptação $(\log a)$ e inclinação (b) da reta, e os seus valores foram: $\log a=$ $-3,3247579$ e $b=2,449888$. Desta forma, tem-se $a=$ $10^{-3,3247579}$.

Substituindo na Equação 16, chega-se a

$$
d_{\mathrm{RPO}}=a S^{b}=0,0004734149844 S^{2,449888} .
$$

\section{Ambiente De Teste}

\section{A. Metodologia}

Para avaliar os modelos propostos foi utilizado um ambiente para realização dos testes, cuja caracteristica é de classe comercial e constituída por único pavimento. Esse ambiente é ocupado por uma empresa de telecomunicações de médio porte e a sua uma planta baixa é apresentada na Figura 1. A localização de cada ponto de medição do sinal WiFi foi feita considerando o plano cartesiano de coordenadas $x$ e $x$, origem está localizada no canto esquerdo inferior da Figura 1. A localização de qualquer objeto no ambiente é determinada por um ponto $(x, y) \operatorname{com} x$ e $y$ positivos. Na figura podem ser 


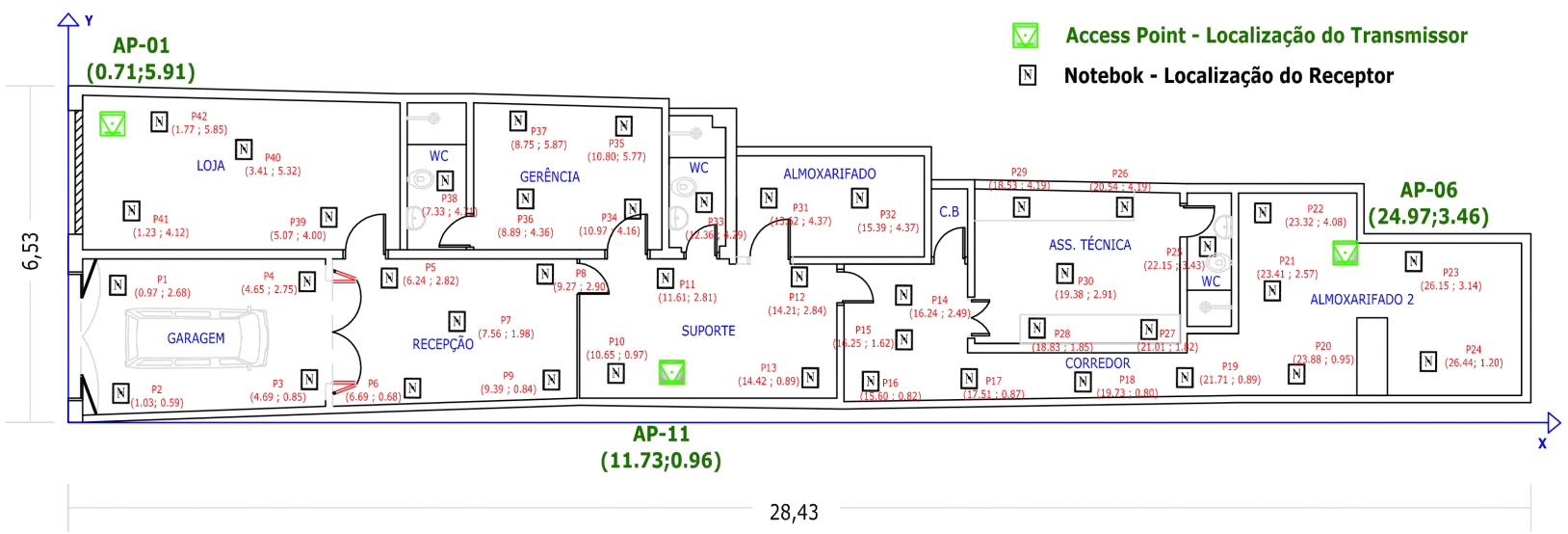

Fig. 1. Planta baixa do ambiente de teste.

indentificados os pontos onde estão localizados os APs bem como os pontos onde foram feitas as medições do sinal com um notebook.

Foram instalados três APs, cuja localização é apresentada na Figura 1. A escolha do canal e do posicionamento dos APs baseou-se na minimização da interferência de um canal sobre o outro. Sabe-se que os sinais desse padrão, IEEE 802.11 b, cobre aproximadamente $22 \mathrm{MHz}$ (sendo espaçado em $5 \mathrm{MHz}$, de um canal para outro) e suporta apenas 3 canais não sobrepostos, logo, os canais escolhidos foram: canal $1(2,412 \mathrm{GHz})$, canal 6 $(2,437 \mathrm{GHz})$ e o canal $11(2,462 \mathrm{GHz})$. Os canais 1 e 6 foram situados em lados opostos enquanto que o canal 11 ficou em um ponto intermediário da construção.

Os APs (modelo WL-1120AP de 11Mbps) foram ajustados para uma potência de saída de $18 \mathrm{dBm}$ na faixa de $2,4 \mathrm{GHz}$. Para realizar a coleta de dados foi utilizado um notebook (Toshiba Satellite A305-S6837 e processador Intel Centrino) com interface de rede sem fio (Atheros Wireless 802.11a/g/n).

O procedimento experimental de coleta de dados foi:

- Escolher uma posição no ambiente para analisar o nível do sinal. Foram utilizados 42 pontos de teste;

- Anotar a localização real na planta baixa, com objetivo de averiguar o erro proposto pelo modelo de perdas por propagação;

- Realizar a leitura dos sinais provenientes de cada AP (canais 1, 6 e 11) e registrar estas informações numa planilha. Para tanto, foi utilizado o programa Network Stumbler.

\section{Resultados}

A seguir serão apresentados os erros dos modelos mencionados na Seção III e os seus respectivos gráficos em relação aos dados obtidos no experimento.

O conjunto de dados experimentais bem como as equações que representam o modelo de Friis para $n=2,0,2,5,3,0$, 3,5, 4,0, 4,5 e 5,0 são apresentadas na Figura 2. A figura tem os dados referentes à distância entre o AP e o ponto de medição

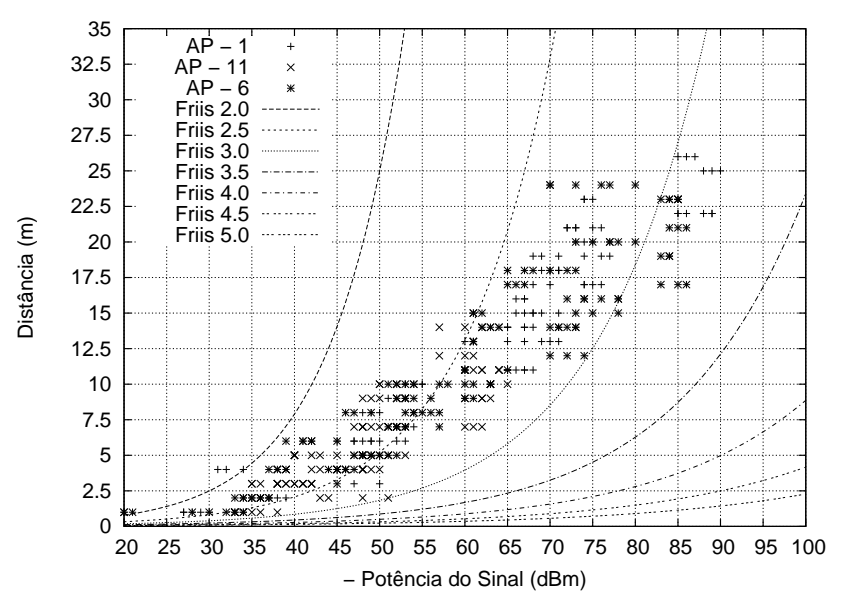

Fig. 2. Distância em função da potência do sinal recebido: dados experimentais e modelo de Friis.

em função da intensidade do sinal recebido. $\mathrm{O}$ erro médio e desvio padrão entre os dados experimentais e o modelo de Friis são apresentados na Tabela II.

TABELA II

ERROS MÉdIO E DESVIO PADRÃo CONSIDERANDO A FÓRMULA DE FRIIS.

\begin{tabular}{c|c|c}
\hline$n$ & Erro Médio (metros) & Desvio Padrão (metros) \\
\hline 2,0 & 204,7 & 408,59 \\
\hline 2,5 & 15,61 & 31,55 \\
\hline 3,0 & 5,72 & 3,11 \\
\hline 3,5 & 8,56 & 4,74 \\
\hline 4,0 & 9,70 & 5,74 \\
\hline
\end{tabular}

A Figura 3 representa a curva da distância em função da potência recebida utilizando o modelo da Recomendação ITUR P.1238-1. O erro médio obtido com esse modelo 7,94 m enquanto que o desvio-padrão é 4,29 m.

O modelo empírico WPS está representado na Figura 4 para o qual o erro médio foi 3,56 m e desvio-pradrão igual a 2,85 


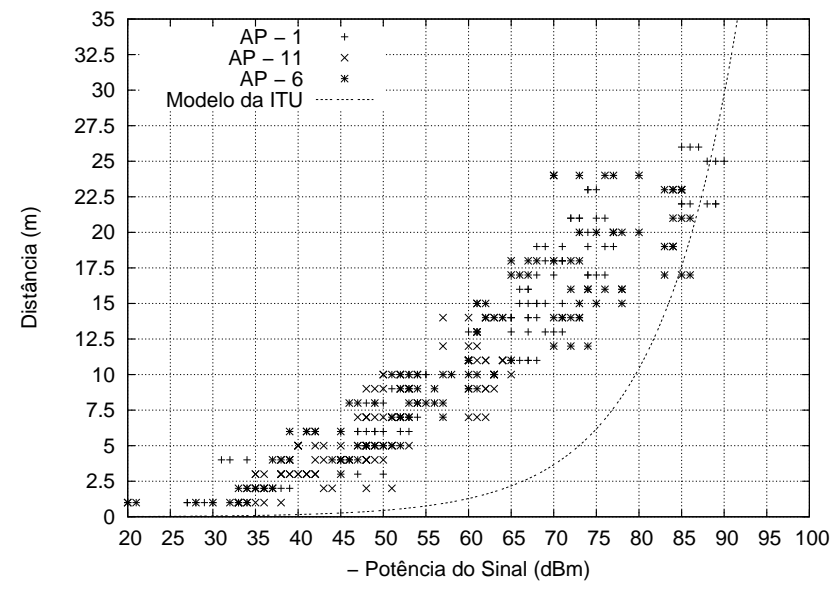

Fig. 3. Distância em função da potência do sinal recebido: dados experimentais e modelo empírico da ITU.

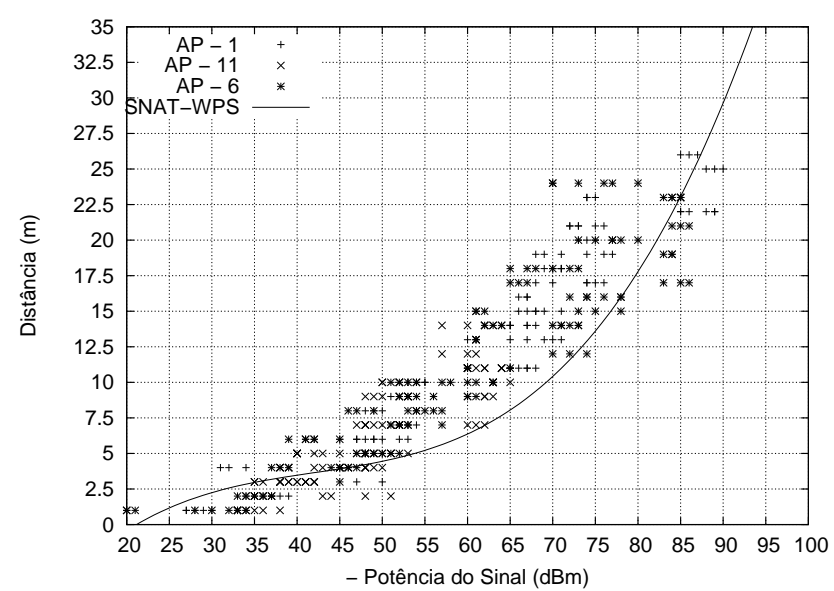

Fig. 4. Distância em função da potência recebida: dados experimentais e modelo empírico WPS.

m.

Após a linearização da Equação 13 e a utilização do método dos mínimos quadrados como técnica de regressão, chega-se à seguinte expressão para o modelo exponencial

$$
d=a e^{b S}=0,657014625 e^{0,045195 S} .
$$

Comparando os valores obtidos com esse modelo e os dados experimentais obtém-se um erro médio igual a 2,39 m com desvio-padrão igual $2,48 \mathrm{~m}$. A Figura 5 representa a curva da distância em função da potência recebida utilizando o modelo proposto de Regressão Exponencial.

A linearização da Equação 16 e a utilização do método dos mínimos quadrados, leva à expressão para o modelo geométrico

$$
d=a S^{b}=0,0004734149844 S^{2,449888}
$$

com erro médio igual a 1,83 m e desvio-padrão igual a 1,53 m.

A Figura 6 representa a curva da distância em função da potência recebida com o modelo proposto de regressão geométrica.

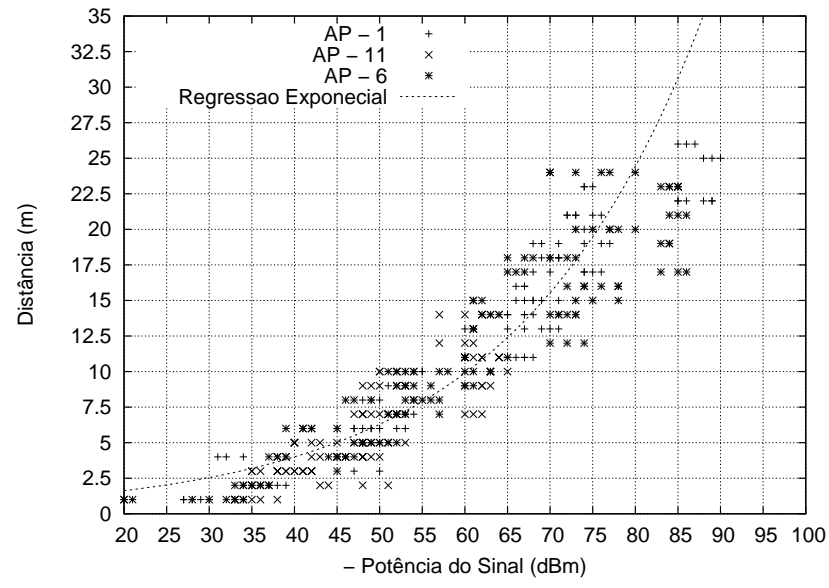

Fig. 5. Distância em função da potência recebida: dados experimentais e regressão exponencial.

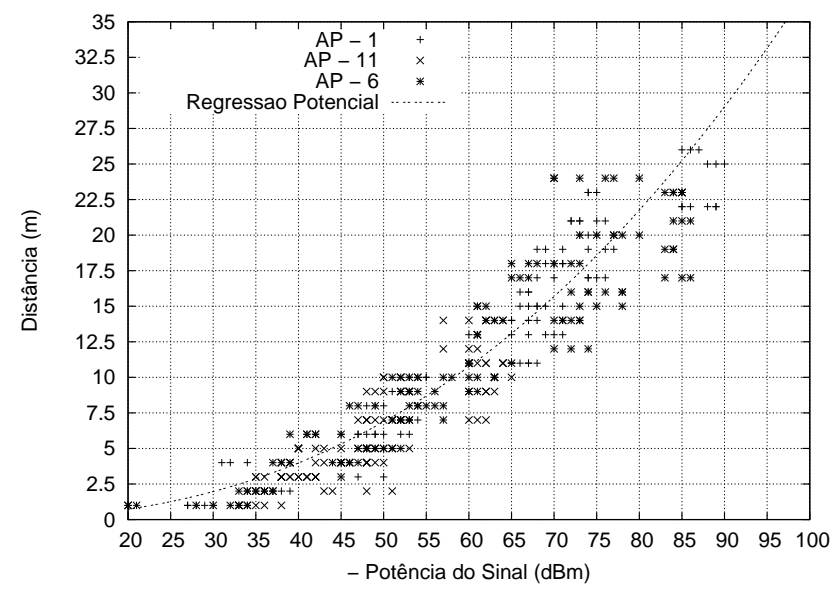

Fig. 6. Distância em função da potência recebida: dados experimentais e regressão geométrica.

De forma resumida, o erro médio, erro máximo e o desviopadrão para cada um dos modelos estudados neste trabalho encontram-se organizados na Tabela III.

\section{CONClus ÃO}

Neste artigo foi proposto um modelo de predição de propagação de sinais $\mathrm{WiFi}$ que pode ser utilizado na construção de um sistema de localização em ambientes fechados. O ambiente montado para obtenção dos dados experimentais foi composto por três pontos de acesso (AP) e um notebook equipado com um cartão WiFi. As medições foram obtidas partindo da premissa que os APs estavam instalados em posições conhecidas. O nível de potência do sinal recebido de cada AP pelo receptor móvel é proposto como um método para estimar a posição do dispositivo móvel. Foram testados alguns modelos empíricos propostos na literatura, entre eles pode-se citar: o modelo de Friis [8], modelo da ITU-T [6] e o modelo WPS [15].

A melhor precisão foi obtida utilizando o modelo WPS que apresentou um erro médio de $3,56 \mathrm{~m}$ e um desvio padrão de $2,85 \mathrm{~m}$. O modelo com melhor precisão levou a se utilizar 
TABELA III

RESUMO COMPARATIVO DOS ERROS.

\begin{tabular}{c|c|c|c}
\hline Modelo & Erro médio $(\mathrm{m})$ & Erro máximo $(\mathrm{m})$ & Desvio-padrão $(\mathrm{m})$ \\
\hline Exponencial & 2,39 & 14,35 & 2,48 \\
\hline Geométrica & 1,83 & 8,42 & 1,53 \\
\hline Friiis $(n=2,0)$ & 204,70 & $2.473,03$ & 408,59 \\
\hline Friis $(n=2,5)$ & 15,61 & 182,24 & 31,55 \\
\hline Friis $(n=3,0)$ & 5,72 & 15,58 & 3,11 \\
\hline Friiis $(n=4,0)$ & 9,70 & 22,53 & 5,74 \\
\hline ITU-T & 7,94 & 20,45 & 4,29 \\
\hline WPS & 3,56 & 13,70 & 2,85 \\
\hline
\end{tabular}

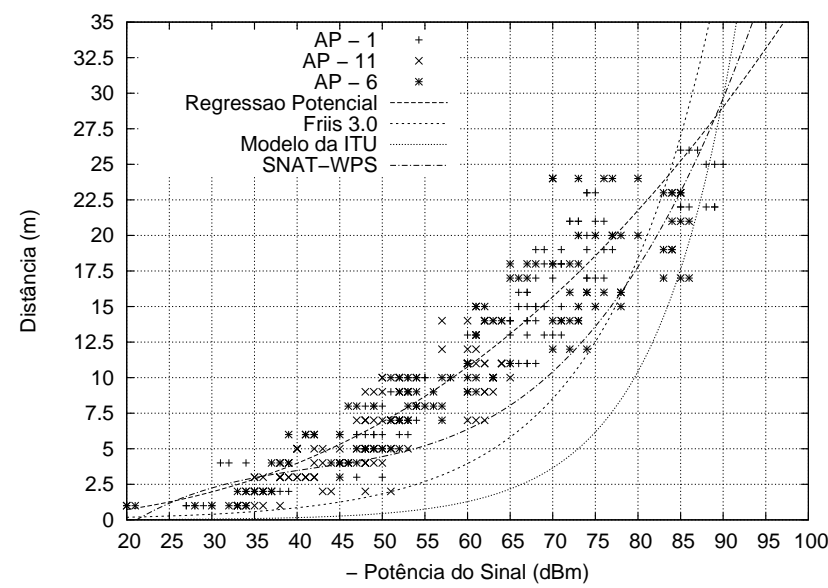

Fig. 7. Comparação entre os modelos da literatura e os propostos.

a técnica de linearização para estimar a curva que melhor representa as informações. Dois tipos de regressão foram utilizados: exponencial e geométrica. $\mathrm{O}$ modelo de regressão que obteve uma melhor precisão foi modelo por regressão geométrica, com um erro médio de $1,83 \mathrm{~m}$ e um desvio padrão de $1,53 \mathrm{~m}$. Mostrou que é possível determinar a localização de um dispositivo móvel usando os sinais de RF de uma rede sem fio.

Como proposta para trabalhos futuros propõe-se a construção de um algoritmo de localização que utilize o modelo de regressão geométrica. Também é interessante realizar um novo estudo, variando o ambiente e aumentando a quantidade de pontos de acesso, para poder formular um modelo genérico que possua alguns parâmetros de ajuste.

\section{REFERÊNCIAS}

[1] ALEnCAR, M. S. Telefonia Celular Digital. 2. ed. São Paulo; Érica, 2007.

[2] BARIZON, B. M. Medidas de Propagação em 2,4 GHz para Planejamento de Redes Locais de Acesso sem Fio. Dissertação de Mestrado, Pontifícia Universidade Católica do Rio de Janeiro, Rio de Janeiro, 2004.

[3] BARRETO, L. C. Mecanismo de Localização de Usuário em ambientes fechados. Dissertação de Mestrado. Universidade Federal da Bahia, Salvador, 2009.

[4] CLARO, P. Sistema de Posicionamento Local Baseado em Redes Wi-Fi. Departamento de Electrónica. Telecomunicações e Informática Universidade de Aveiro, 2007. Disponivel em: http://www.av.it.pt/nbcarvalho/pdf/localwifi_slides.pdf. Acessado em: maio de 2008.
[5] FERREIRA, M C S: INTELLIWATTS - Gerenciamento Inteligente de Energia para Dispositivos Computacionais. Dissertação de Mestrado, Universidade Federal da Bahia, Salvador, 2009.

[6] ITU-R P.1238-1: "Proopagation data and Prediction Models for the Planning of Indoor Radiocommunication Systems and Radio Local Area Networks in the range $900 \mathrm{MHZ}$ to $100 \mathrm{GHz}$, 1997-1999-2001.

[7] JESUS, R M: Modelos e Planeamento para Redes Locais de Acesso Via Rádio, Trabalho de Conclusão de Curso, Instituto Politécnico de Lisboa, Lisboa, 2004.

[8] MOTLEY A. J; KENNAN, J. M. Personal Communication Radio Coverage in Buildings at $900 \mathrm{MHz}$ and $1700 \mathrm{MHz}$, IEEE Electronic Letters, v.24, pp. 763-764, Junho de 1988.

[9] MOURA, A. I. WBLS: Um Sistema de Localização de Dispositivos Móveis em rede Wi-FI. Dissertação de Mestrado, Escola Politécnica da Universidade de São Paulo, São Paulo, 2007.

[10] NASCIMENTO, F N C: Um Serviço para Inferência de Localização de Dispositivos Móveis Baseado em Redes IEEE 802.11. Dissertação de Mestrado, Pontifícia Universidade Católica do Rio de Janeiro, Rio de Janeiro, 2005 .

[11] OLIVEIRA, R P; CAMPOS, R L: Projecto de Redes Locais Sem Fios 802.11b - Análise de Localização. Departamento de Engenharia Electrotécnica e de Computadores, INESC Porto/FEUP, 2003.

[12] PACHECO, H.; ANDRADE, G. Sistema de Localização em Ambientes Fechados. PFC, 2007. Disponível em: http://www.deetc.isel.ipl.pt. Acessado em abril de 2008.

[13] PORTELA, J N: Planejamento Celular Usando Diagramas de Voronoi. Tese de Doutorado, Universidade Federal de Campina Grande, Paraíba, 2006.

[14] WANG, Y; JIA X; LEE, H K; LI G Y. An Indoors Wireless Positioning System Based on Wireless Local Area Network Infrastructure. The 6th International Symposium on Satellite Navigation Technology Including Mobile Positioning \& Location Services, 2003.

[15] YACOUB, M. D. Foundations of Mobile Radio Engineering. Boca Raton, FL, USA: CRC Press, Inc. 1993. 